\title{
Nucleotide Analogue GS 9219
}

National Cancer Institute

\section{Source}

National Cancer Institute. Nucleotide Analogue GS 9219. NCI Thesaurus. Code C71742.

A prodrug of the acyclic nucleoside phosphonate analogue 9-(2-

phosphonylmethoxyethyl)guanine (PMEG) with potential antineoplastic activity.

Formulated to selectively accumulate in lymphocytes, nucleotide analogue GS 9219 is

converted to its active metabolite, PMEG diphosphate (PMEGpp), via enzymatic

hydrolysis, deamination, and phosphorylation; subsequently, PMEGpp is incorporated into

nascent DNA chains by DNA polymerases, which may result in the termination of DNA

synthesis, S-phase cell cycle arrest, and the induction of apoptosis in susceptible

lymphoma cell populations. 